\title{
Hilar Area of the Lung
}

National Cancer Institute

\section{Source}

National Cancer Institute. Hilar Area of the Lung. NCI Thesaurus. Code C49282.

The wedge-shaped area at the central portion of the lung through which the bronchi, vessels and nerves enter or exit the organ. 